\title{
The Long-Run Phillips Curve: A Structural VAR Investigation*
}

\author{
Luca Benati \\ University of Bern ${ }^{\dagger}$
}

\begin{abstract}
I use structural VARs identified based on either long-run restrictions, or a combination of long-run and sign restrictions, to investigate the long-run tradeoff between inflation and the unemployment rate in the U.S., the Euro area, the U.K., Canada and Australia over the post-WWII period.

Results based on VARs featuring a single permanent inflation shock do not allow to reject the null hypothesis of a vertical long-run Phillips curve for either country. Results based on VARs allowing for four permanent inflation shocks, which are sorted out from one another by means of DSGE-based robust sign restrictions, produce a very similar picture. The overall extent of uncertainty is however substantial, thus suggesting that the data are compatible with a comparatively wide range of possible slopes of the long-run trade-off.

For all countries, Johansen's cointegration tests point towards the presence of cointegration between either inflation and unemployment, or inflation, unemployment, and a short-term interest rate, with the long-run Phillips trade-off implied by the estimated cointegrating vectors being negative and sizeable. I argue however that this evidence should be discounted, as, conditional on the estimated structural VARs - which, by construction, do not feature cointegration between any variable - Johansen's procedure tends to spuriously detect cointegration a non-negligible, and sometimes large, fraction of the times.
\end{abstract}

Keywords: Phillips curve; unit roots; cointegration; Bayesian VARs; structural VARs; long-run restrictions; sign restrictions.

\footnotetext{
${ }^{*}$ I wish to thank the Co-Editor (R. Reis) and an anonymous referee for extremely helpful comments and suggestions. Thanks to F. Canova and R. Cooper for helpful discussions; J. Carrillo, H. Uhlig and seminar participants at CREST, the European University Institute, Norges Bank, the Swiss National Bank's 2012 research conference 'Policy Challenges and Developments in Monetary Economics', and the 2013 Workshop on Empirical Macroeconomics held at the University of Ghent for comments; and J. Rubio-Ramirez for helpful suggestions. Usual disclaimers apply.

${ }^{\dagger}$ Department of Economics, University of Bern, Schanzeneckstrasse 1, CH-3001 Bern, Switzerland. Email: luca.benati@vwi.unibe.ch
} 


\section{Introduction}

In spite of the central role played by the unemployment-inflation trade-off in shaping the evolution of both macroeconomic thinking ${ }^{1}$ and policymaking over the last several decades, surprisingly little econometric work has been devoted to investigating the nature of the long-run trade-off. In particular, as I discuss more extensively below, to the best of my knowledge the only existing investigation of the long-run Phillips trade-off based on structural VAR methods is King and Watson (1994)'s 'revisionist econometric history' of the post-WWII U.S. Phillips curve, which has produced evidence of a negative, and statistically significant long-run trade-off conditional on aggregate demand-side shocks.

In this paper I use both Classical and Bayesian structural VARs identified based on either long-run restrictions, or a combination of long-run and sign restrictions, in order to investigate the long-run trade-off between inflation and the unemployment rate in the U.S., the Euro area, the U.K., Canada and Australia over the post-WWII period.

Results based on Classical VARs featuring a single permanent inflation shock do not allow to reject the null hypothesis of a vertical long-run Phillips curve for either country, with both the modes and the medians of the bootstrapped distributions of the long-run impact on unemployment of a one per cent permanent shock to inflation being close to zero. Applying the same identification strategy within a Bayesian context produces results which are numerically very close to those produced by Classical methods, pointing, once again, towards no long-run unemployment-inflation trade-off.

Since, in principle, these results are not incompatible with the notion that some of the shocks exerting a permanent impact on inflation may induce a non-zero long-run Phillips trade-off, working within a Bayesian context I then proceed to disentangle permanent inflation shocks into demand- and supply-side ones, by imposing Canova and Paustian's (2011) DSGE-based 'robust sign restrictions' on their impact on the endogenous variables at $t=0$. Overall, results are qualitatively similar to the one produced by VARs featuring a single permanent inflation shock. In particular,

( $i$ ) for all countries, and for either shock, the 90\%-coverage percentiles of the posterior distributions of the long-run impact on the unemployment rate of a one per cent permanent shock to inflation contain zero, thus implying that the notion of a vertical long-run Phillips curve cannot be rejected at conventional significance levels.

(ii) For either shock, both the modes and the medians of the posterior distributions of the long-run impact on unemployment of a one per cent permanent shock to inflation are, in general, close to zero.

An important point to stress, however, is that the overall extent of uncertainty is substantial, thus suggesting that the data are compatible with a comparatively wide range of possible slopes of the long-run trade-off. This is the case both for the Classical and Bayesian VARs featuring a single permanent inflation shock, and, especially, for

\footnotetext{
${ }^{1}$ See in particular Lucas (1972a), Lucas (1972b), and Lucas (1973).
} 
the Bayesian VARs allowing for multiple shocks exerting a permanent impact on inflation. For the U.S., for example, the $90 \%$ bootstrapped confidence interval for the estimated long-run impact on the unemployment rate of a one per cent permanent shock to inflation produced by Classical VARs featuring a single permanent inflation shock stretches between -0.56 and 0.15 . The key reason for such a comparatively large extent of uncertainy is that the feature of the data we are attempting to estimate pertains to the infinite long run, and, as it is well known - see e.g. Faust and Leeper (1997) - this is bound to produce imprecise estimates, unless the researcher is willing to impose upon the data very strong restrictions (which, in general, is not advisable). In the case of the VARs allowing for four permanent inflation shocks, this problem is compounded by our use of sign restrictions, which, as stressed by Fry and Pagan (2011), are intrinsically 'weak information', and should therefore not be expected to produce strong inference.

For all countries, Johansen's cointegration tests point towards the presence of cointegration between either inflation and unemployment, or inflation, unemployment, and a short-term interest rate, with the long-run Phillips trade-off implied by the estimated cointegrating vectors being negative and sizeable. As I show via Monte Carlo, this is not the product of the comparatively short samples I am working with, as the fraction of simulations for which the bootstrapped trace statistic incorrectly rejects the null of no cointegration between two independent random walks at a given significance level ranges between 11.3 and 11.9 per cent at the 10 per cent level; between 5.5 and 6.0 per cent at the 5 per cent level; and between 1.1 and 1.3 per cent at the 1 per cent level, thus pointing towards an excellent performance of the cointegration procedure I am using herein (which largely originates from the bootstrap's ability to effectively take into account of the specific characteristics of the data generation process under investigation). I argue however that this evidence should be discounted, as, conditional on the estimated structural VARs - which, by construction, do not feature cointegration between any variable - Johansen's bootstrapped procedure tends to spuriously detect cointegration a non-negligible fraction of the times. For example, for the Euro area and the U.K., conditional on taking the VARs featuring four permanent inflation shocks as data generation processes, the fractions of bootstrapped $p$-values for Johansen's trace statistic for testing the null of no cointegration between inflation and the unemployment rate which are smaller than 10 per cent are equal to 0.269 and 0.236 per cent respectively. This means that, if the estimated structural VARs were the true data-generation process, Johansen's trace test would incorrectly reject the null of no cointegration between inflation and unemployment at the 10 per cent level about one-fourth of the times.

\subsection{Related literature}

To the very best of my knowledge, the only existing investigation of the long-run Phillips trade-off based on structural VAR methods is King and Watson's (1994) 
'revisionist econometric history' of the post-WWII U.S. Phillips curve. King and Watson (1994) estimate a bivariate VAR for the first differences of CPI inflation and the unemployment rate for the period 1954-1992, and explore the long-run tradeoff induced by aggregate demand-side permanent shocks to inflation based on three alternative identification schemes. Results based on the identification scheme they regard as more reliable (which they label as 'Rational Expectations Monetarist') point towards a negative, statistically significant, and comparatively flat long-run Phillips trade-off for either the full sample period, or the 1970-1992 sub-sample (with point estimates equal to -0.29 and -0.23 , respectively), and to a steeper trade-off for the 1954-1969 sub-sample (with a point estimate of -0.47).

Nearly two decades after King and Watson (1994), there are several reasons why it is of interest to reconsider this issue.

First, their finding of a negatively sloped, statistically significant, and comparatively flat long-run Phillips curve has radical implications for the conduct of monetary policy, as it implies that the current consensus, within the central banking community, that there is no long-run trade-off between inflation and economic activity - with its corollary that the central bank should focus on delivering low and stable inflation - is misplaced. Current monetary frameworks have been built around the notion that there is no long-run trade-off which can be exploited by monetary policy: in spite of its strong conceptual appeal, it is important to know whether such a notion is in fact supported by empirical evidence.

Second, in the years since 1994 structural VAR econometrics has seen important developments in terms of identification. When King and Watson wrote, short-run restrictions were still either of the 'inertial' type - that is, based on imposing zeros in the impact matrix of the structural shocks at $t=0$ - or they were based on the notion of 'calibrating' some of these impacts based on information extraneous to the VAR. $^{2}$ In recent years, several contributions have highlighted the dangers associated with the former approach, ${ }^{3}$ whereas the reliability of the latter crucially hinges, as a matter of logic, on just how credible the numbers the researcher is imposing in the VAR's structural impact matrix truly are. Since imposing a specific number entails making a very strong assumption-implying an extent of knowledge we typically

\footnotetext{
${ }^{2}$ Indeed, this is how King and Watson (1994) achieved identification in their preferred specification. As stressed by Evans (1994) in his comment on King and Watson (1994),

'[i]dentification of the supply and demand shocks is achieved by imposing a value for $\lambda$ [the parameter which determines the impact of demand shocks on the unemployment rate at $t=0]$ a priori in the empirical analysis.'. (See Evans, 1994, p. 222.)

${ }^{3}$ The work of Fabio Canova and his co-authors, in particular (see, first and foremost, Canova and Pina, 2005) has demonstrated that, since inertial restrictions are, in general, incompatible with the structure of general equilibrium models - in the specific sense that, within DSGE models, the impact matrix of the structural shocks at $t=0$ is, in general 'full', i.e., it has no zero entries -imposing such zeros can lead to dramatically distorted inference, for example 'uncovering' price puzzles which are not in the data generation process.
} 
do not have - an alternative style of identification based on weaker informational requirements might be regarded as preferrable. Several researchers ${ }^{4}$ have therefore proposed sign restrictions - that is, restrictions on the signs of the impacts of the structural shocks at $t=0$, and possibly on their impulse-response functions at longer horizons - as the best (or least bad ...) way of achieving identification based on shortrun restrictions. As shown by Canova and Paustian (2011), indeed, DSGE models often imply a robust pattern of signs for the impacts of the structural shocks at $t=0$ (where 'robust' means that such pattern holds true for alternative sub-classes of DSGE models, and for a wide range of plausible parameters' configurations), which is often sufficient to disentangle the structural shocks from one another. In fact, when seen from the perspective of DSGE models, a specific pattern of signs for the impacts of the structural shocks at $t=0$ is typically the only kind of information we can be reasonably confident about, whereas the specific values taken by such impacts are, in general, much more uncertain, thus raising doubts on the reliability of an approach to identification based on the notion of calibrating such impacts. ${ }^{5}$

Third, King and Watson's analysis was entirely based on a bivariate VAR for the first differences of inflation and the unemployment rate, but, as shown by Evans (1994) in his comment, ${ }^{6}$ even based on their identification strategy, evidence based on trivariate VARs was sometimes significantly different, pointing in some cases towards a vertical long-run Phillips curve. This naturally suggests reconsidering the issue based on VARs featuring a broader informational content, in particular about the stance of monetary policy and the state of the business cycle. ${ }^{7}$

\section{Three Alternative Forms of the Long-Run Phillips Curve}

In what follows we consider three alternative forms of the long-run Phillips curve (henceforth, LRPC).

\footnotetext{
"See in particular Faust (1998), Canova and de Nicolo' (2002), and Uhlig (2005).

${ }^{5}$ An approach to identification based on sign restrictions is not without problems of its own. As extensively discussed by Fry and Pagan (2011), in particular, sign restrictions suffers from the shortcoming that they are intrinsically 'weak information', and therefore they should not be expected to produce strong inference.

${ }^{6}$ See Evans (1994, Section 3.2, and in particular the results reported in Figure 2).

${ }^{7}$ For the reason discussed, e.g., by Sargent (1987) - that is: the first-difference filter wipes out most of the variance at the business-cycle frequencies - the fact that, as it is well known, the level of the U.S. unemployment rate is highly informative about the state of the U.S. business cycle logically implies that its first difference is not. This means that a VAR for the U.S. which, beyond the firstdifference of the unemployment rate, does not include other indicators of real economic activity, does not contain strong information about the state of the business cycle.
} 


\subsection{A strong-form LRPC}

First, we consider a 'strong form of the LRPC', in which inflation and the unemployment rate are (possibly) cointegrated. Such a strong form implies that $(i)$ all shocks having a permanent impact on inflation also have a permanent impact on the unemployment rate (and vice versa), and ( $i i)$ for either of these shocks, the ratio between the long-run impacts on the two variables is exactly the same (thus implying that inflation and unemployment share the same stochastic trend across all possible shocks).

We investigate whether the data are consistent with such a strong from of the LRPC via standard cointegration methods.

\subsection{A medium-form LRPC}

Since either $(i)$ or (ii) may well be violated, we also consider two weaker forms of the LRPC, starting from a 'medium-form LRPC' conceptually in line with King and Watson (1994), in which the unit root component of the unemployment rate is driven by both idiosyncratic shocks, and permanent shocks to inflation. It is not difficult to think of circumstances under which this may be the case. For example, permanent shocks to the tax rate on labor should lead to increases in the natural rate of unemployment, but - being shocks to the level of the tax rate, as opposed to its rate of change - they should only have a transitory impact on inflation. By the same token, given the widely documented stylized fact that unemployment rates differ systematically by age/sex/race groups, secular changes in the composition of the labor force should lead to permanent changes in the overall natural rate of unemployment, but at the same time they should not have any permanent impact on inflation. So the bottom line is that it is pretty easy to think of circumstances in which the strong form of the LRPC does not hold, but the medium-form may hold.

In the spirit of King and Watson (1994), in what follows we will search for a medium-form LRPC based on structural VARs featuring, beyond the first differences of inflation and unemployment, a measure of the output gap, the consumption/GDP ratio, a long-short spread, and (the first difference of) the short-term monetary policy rate. These variables effectively expand the informational content of King and Watson's original bivariate VAR along several dimensions. The short rate and, to a lesser extent, the long-short spread contain information about the monetary policy stance. As recently shown by Kurmann and Otrok (2013), the long-short spread possesses a strong informational content for future movements in technology. Finally, the consumption/GDP ratio and the output gap measure can be regarded as two "noisy estimates' of the state of the business cycle. We consider these additional variables for two reasons. First, King and Watson's analysis was entirely based on a bivariate VAR for the first differences of inflation and the unemployment rate, but, as shown by Evans (1994) in his comment, even based on their identification strategy, evidence based on trivariate VARs was sometimes significantly different, pointing in some cases 
towards a vertical long-run Phillips curve. Second, as recently discussed by Forni and Gambetti (2014), small VARs with a limited informational content may well produce unreliable results. We will identify a single, 'aggregate' permanent inflation shock via standard long-run restrictions, and we will then explore whether such a shock has a non-zero long-run impact on the unemployment rate.

\subsection{A weak-form LRPC}

Since, in principle, absence of a long-run trade-off conditional on such 'aggregate' permanent inflation shock is not incompatible with the notion that some of the shocks exerting a permanent impact on inflation may induce a non-vertical LRPC, we then proceed to explore a 'weak-form LRPC', in which either of these shocks is allowed to give rise to an idiosyncratic trade-off. Specifically, we disentangle permanent inflation shocks into demand- and supply-side ones by imposing Canova and Paustian's (2011) DSGE-based 'robust sign restrictions' on their impact on the endogenous variables at $t=0$, and we proceed to explore whether any of these shocks has a statistically significant long-run impact on the unemployment rate. Although we identify four different shocks having a permanent impact on inflation, we mostly focus upon shocks of a monetary nature. The reason for doing so is that the motivation behind all explorations of the slope of the LRPC has always been understanding whether the monetary authority might be able to permanently lower the unemployment rate by engineering a permanently higher rate of inflation. Under this respect, the long-run Phillips trade-offs which might originate from permanent inflation shocks of a nonmonetary nature are therefore irrelevant. The framework used in order to explore the weak-form LRPC has an obvious connection to the one used to explore the mediumform one. Whereas, by construction, the permanent inflation shocks identified by the 'medium-form LRPC' VAR explain 100 per cent of the infinite long-run variance of inflation, the four permanent inflation shocks identified by the 'weak-form LRPC' VAR jointly explain all of the long-run variance of inflation (in particular, in most cases permanent inflation shocks of a monetary nature are essentially negligible).

\section{The Data}

As discussed by King and Watson (1994), the possibility of identifying the long-run impact on the unemployment rate of permanent inflation shocks crucially hinges on the fact that both series contain an I(1) component. As documented by Benati (2008), however, evidence of high inflation persistence is weak-to-non-existent for all sample periods which are not dominated by the Great Inflation episode (and especially so for monetary regimes such as inflation targeting). In what follows I therefore consider the following sample periods: for the Euro area, 1970Q1-1998Q4 (EMU started in January 1999, whereas Euro area data are only available starting from 1970Q1); for the U.K., 1972Q2-1992Q3 (June 1972 marks the floating of the pound vis-à-vis the U.S. dollar, 
whereas inflation-targeting was introduced in October 1992) ${ }^{8}$ for Canada, 1961Q21990Q4 (inflation targeting was introduced in February 1991, whereas 1961Q1 is when Canadian national account data first become available); for Sweden 1970Q1-1992Q4 (inflation targeting was introduced in January 1993, whereas the unemployment rate is only available since 1970Q1); for Australia, 1969Q3-1994Q2 (the current inflation targeting regime was never clearly announced, and we therefore follow Bernanke et al., 1999, in marking its start in 1994Q3; the short rate is available since 1969Q3); and for Japan the period following the collapse of Bretton Woods (since 1971 the Japanese government has not explicitly introduced any new monetary regime, and has instead relied on a generic committment to price stability). Finally, for the U.S., as I discuss below, I consider several alternative sample periods.

\subsection{Results from unit root tests}

Table 1 reports, for either country, bootstrapped p-values for Elliot et al.'s (1996) unit root tests for inflation, the unemployment rate, and the short-term interest rate. For either series, $p$-values have been computed by bootstrapping 10,000 times estimated $\operatorname{ARIMA}(p, 1,0)$ processes. In all cases, the bootstrapped processes are of length equal to the series under investigation. As for the lag order, $p$, since, as it is well known, results from unit root tests may be sensitive to the specific lag order which is being used, for reasons of robustness we consider four alternative lag orders, 2, 4, 6 and 8 quarters (for the U.S., for which we use monthly data, the corresponding lag orders are $6,12,18$, and 24$)$.

Based on either the CPI or the GDP deflator, the null of a unit root in inflation cannot be rejected for either the Euro area, the U.K., Canada, or Australia, with the $p$-values being uniformly greater than 10 per cent, in most cases comfortably so. Evidence for Sweden, on the other hand, is not clear-cut, with the $p$-values ranging between 0.012 and 0.215 . Evidence for Japan is likewise inconclusive, with the $p$ values ranging between 0.069 and 0.331 based on the CPI, and between 0.040 and 0.396 based on the GDP deflator. Because of such a comparatively weak evidence of a unit root in inflation for either Japan or Sweden, in what follows I exclude these countries from the analysis. Finally, for the U.S. evidence of a unit root based on the entire sample period since January 1959 is strong based on the PCE deflator, and it is just slightly less so based on the GDP deflator (with the $p$-value for $p=2$ being equal to 0.039). Splitting the full sample in August 1979, however, clearly shows how evidence of a unit root entirely originates from the pre-Volcker period (for which the smallest $p$-value, across price indices and lag orders, is equal to 0.414 ), and it is instead absent from the second sub-period, for which the $p$-values are uniformly very low. This clearly suggests that results for the U.S. based on the full sample period should be viewed with suspicion, and in what follows I will therefore uniquely focus

\footnotetext{
${ }^{8}$ As shown by Benati (2008), before the June 1972 floating of the pound U.K. inflation exhibited quite significantly lower persistence.
} 
on the pre-Volcker period.

Evidence of a unit root in the unemployment rate is strong for either the Euro area, the U.K., Canada, or Australia. For the U.S., evidence is compatible with the notion that the unemployment rate contains a unit root in both sub-periods, whereas results for the entire sample period are weak.

As previously mentioned, one possible limitation of King and Watson's (1994) analysis was its bivariate nature, and its eschewing of information on the monetary policy stance and the state of the business cycle. Beyond the first differences of inflation and the unemployment rate, in what follows I therefore also include, in the VAR, an output gap measure, the consumption/GDP ratio, a long-short spread, and either the level or the first difference of a short-term interest rate. As for the output gap measure, the consumption/GDP ratio, and the spread, Elliot et al.'s (1996) tests clearly point towards these series being stationary (we do not report these results for reasons of space, but they are available upon request). As for the short rate, the evidence in Table 1 strongly points towards a unit root for all countries, and based on either lag order, with the single exception of the U.K. for which $p$-values range between 0.007 and 0.040 . In what follows, the short rate will therefore enter the VAR in levels for the U.K., and in first differences for all other countries.

Finally, for reasons of robustness we have also considered tests based on Phillips' $Z_{\rho}$ and $Z_{t}$ statistics. $^{9}$ The tests have been performed based on estimated models including an intercept, but no time trend, and bootstrapped $p$-values have been computed as before. Again for reasons of robustness, we have considered four values for $Q$, the maximum number of autocovariances to be considered for Phillips' tests, that is, 2, 4, 6 and 8 quarters (for the U.S. the corresponding values of $Q$ are $6,12,18$, and 24). Table A.1 in the online appendix reports results for the $Z_{\rho}$ statistic, whereas results for the $Z_{t}$ tests are not reported both for reasons of space, and because they are uniformly in line with those from the $Z_{\rho}$ tests. These results are almost uniformly in line with those from Elliot et al.'s tests. The main difference - which is however irrelevant for our purposes - pertains to U.S. inflation for the full sample period since January 1959, for which the null of a unit root is strongly rejected (on the other hand, in line with the results from Elliot et al.'s tests, results for the pre-Volcker period clearly point towards a unit root in U.S. inflation based on either price index).

\footnotetext{
${ }^{9}$ In performing Phillips' tests, we compute the weighted sum of the autocovariances $\hat{\lambda}_{\tau}$ (see e.g. the expression towards the bottom of page 557 of Gregory and Hansen (1996)) based on a Bartlett kernel, selecting the bandwidth parameter via the procedure proposed by Beltrao and Bloomfield (1987).
} 


\section{Evidence}

\subsection{Results based on cointegration analysis}

Table 2 reports bootstrapped ${ }^{10} p$-values for Johansen's trace test of the null of no cointegration between either inflation and unemployment, inflation and the short rate (with the single exception of the U.K., for which results from unit root tests strongly reject the null of a unit root in the short rate), or inflation, the unemployment rate, and the short rate. $p$-values have been computed by bootstrapping the VAR estimated for the first difference of the relevant vector of series (so, to be clear, the VAR which is being bootstrapped is not a cointegrated VAR, that is, it is equal to the VECM representation without the error-correction term). Given the vector of the relevant series $Y_{t}$, we start by selecting the lag order for cointegration tests as the maximum between the lag orders selected based on the Schwartz and the HannanQuinn criteria (we eschew the AIC since, with $\mathrm{I}(1)$ variables, it is an inconsistent lag selection criterion, see Luetkepohl (1991)), and we perform Johansen's trace test of the null of no cointegration. Then, we estimate the VAR for $\Delta Y_{t}$; we bootstrap it 10,000 times, thus generating bootstrapped artificial series $\Delta \tilde{Y}_{t}^{j}$; based on each of them we compute corresponding bootstrapped artificial series $\tilde{Y}_{t}^{j}$ (that is, those for the levels of the series); and finally, based on each of them we perform the same trace test we previously computed based on the actual data, thus building up the empirical distribution of the trace statistic under the null of no cointegration. Based on this distribution, we then compute critical values (not reported here) and $p$-values.

For the U.S. we detect no evidence of cointegration between inflation and the unempoyment rate. On the other hand, we detect strong evidence of cointegration between inflation and the Federal Funds rate, with a $p$-value equal to 0.0069. This is consistent with Barsky's (1987) findings on the appearance, for the first time, of a Fisher effect in U.S. data for the post-WWII sample period comprising the Great Inflation episode (working in the middle of the Great Inflation episode, and therefore with less information that Barsky, Fama (1975) produced very similar evidence for the period 1953-1971). The median estimate of the second normalized element of the cointegrating vector is -1.018 , with the $p$-value for rejecting the null hypothesis that the cointegration vector is $[1 ;-1]$ being equal to 0.423. For the Euro area, Canada, and Australia on the other hand, bivariate cointegration tests do not detect any evidence of cointegration between inflation and the short rate. Although at first sight

\footnotetext{
${ }^{10}$ Since I am here bootstrapping critical and $p$-values, my results are robust to $(i)$ the possible non-normality of the shocks, and ( $i i)$ small-sample problems. As for the former issue, under very general conditions the residuals of the VAR estimated under the null of no cointegration are consistent estimates of the true underlying shocks, in the sense that they do converge to such shocks in probability limit. As a result, the underlying shocks may have, in population, any non-degenerate distribution we can think of, because bootstrapping the residuals automatically takes care of that. As for the latter issue, as I discuss in Section 8.1.1 below, bootstrapping effectively takes care of that, too.
} 
puzzling - taken at face value, these results imply a rejection of the Fisher hypothesis that permanent shifts in inflation should map one-to-one into corresponding shifts in interest rates - it ought to be stressed that empirical evidence on the violation of the Fisher hypothesis is widespread (after all, the key reason why Fama's (1975) paper had such a resonance was precisely because it produced, for the first time, decisive evidence in favor of the Fisher effect). This implies that these results should not be seen as surprising at all. Finally, for either the U.S., the Euro area or, Canada we detect strong evidence of cointegration between inflation, unemployment, and the short rate, whereas for the U.K. evidence points, at the 10 per cent level, towards cointegration between inflation and the unemployment rate.

For the U.S., the Euro area and Canada, for which we detected evidence of cointegration between the three series, we also report bootstrapped $p$-values for testing the null hypothesis of one single cointegrating vector, versus the alternative of two cointegrating vectors. Details of the bootstrapping procedure are the same as before, with the only difference that, instead of bootstrapping the estimated VAR for $\Delta Y_{t}$ under the null of no cointegration, we bootstrap the VECM estimated conditional on there being one single cointegrating vector. Whereas the $p$-value for Canada, at 0.2896, is very far from being significant at any conventional level, those for the Euro area and the U.S., at 0.0531 and 0.0728 , respectively, point towards the presence of an additional cointegrating vector at the 10 per cent level.

For the Euro area and the U.K., for which we detected evidence of cointegration in the bivariate representation for $Y_{t}=\left[\pi_{t}, U_{t}\right]^{\prime}$ at the 5 per cent level, Figure 1 reports the bootstrapped distributions of the ratio between the permanent impacts of the common shock on the unemployment rate and inflation, respectively, and of the elements of the loading vector of the cointegrating residual in the VECM representation. For either country, the long-run impact on the unemployment rate induced by the common shock (normalized in such a way as to induce a one per cent permanent increase in inflation) is highly statistically significantly different from zero, as implied by the results from the trace test, and as testified by the fact that mass of the bootstrapped distribution is pretty much away from zero. Further, the estimated impact is also sizeable, with median estimates equal to -1.074 for the Euro area, and -1.537 for the U.K., and 90 per cent-coverage bootstrapped confidence intervals equal to $[-1.327 ;-0.866]$ and $[-2.278 ;-0.759]$, respectively.

Taken at face value, these results point towards the presence of a negative and sizeable long-run trade-off induced by the common permanent shock in both the Euro area and the U.K.. The next two sub-sections provide some perspective on this, by (i) exploring the extent to which these results may just be statistical flukes, and then (ii) focusing on whether - even assuming that they are genuine - they are in fact compatible with the notion of a trade-off which can be exploited by policymakers in order to permanently decrease the unemployment rate by engineering a permanently higher rate of inflation. 


\subsubsection{Monte Carlo evidence on the performance of Johansen's procedure}

The case of two independent random walks A first possibility is that the results for the Euro area and the U.K. are a statistical fluke due to the bad performance of Johansen's procedure in small-samples. In order to assess this possiblity we consider five sets of 10,000 Monte Carlo simulations of lengths equal to the actual sample lengths we are working with for the five countries. For each simulation, we randomly generate two independent random walks, and we apply exactly the same procedure we previously applied to the actual data, computing the $p$-values by bootstrapping the estimated VAR for the first differences of the two random walks. Ideally, out of the 10,000 simulations, the fraction of bootstrapped $p$-values below $x$ per cent should be equal to $x$ per cent. As the results reported in Table A.2 in the online appendix clearly show, the bootstrapped Johansen procedure we are using herein gets quite remarkably close to this ideal: the fraction of simulations for which the bootstrapped trace statistic incorrectly rejects the null of no cointegration between the two independent random walks at a given significance level ranges between 11.3 and 11.9 per cent at the 10 per cent level; between 5.5 and 6.0 per cent at the 5 per cent level; and between 1.1 and 1.3 per cent at the 1 per cent level. Quite remarkably, the performance for the U.K., for which we have just 81 quarterly observations, is not dramatically different from that for Canada, for which we have instead 118 observations. This testifies to the power of bootstrapping, which can effectively take into account of the specific characteristics of the data the researcher is working with.

Taking the non-cointegrated structural VARs as data-generation processes Although the bootstrapped Johansen procedure used herein performs remarkably well conditional on a data-generation process (henceforth, DGP) in which the series of interest are independent random walks, it is an open question how well such a procedure performs conditional on DGPs such as the non-cointegrated structural VARs featuring permanent inflation shocks we will estimate in Sections 4.2 and 4.3, respectively. Since these results will produce no evidence whatsoever of a long-run Phillips trade-off conditional on any kind of permanent inflation shock, it is of interest to explore the performance of Johansen's procedure conditional on these DGPs. To put it differently, suppose that these structural VARs are, for either country, the true model of the economy: how often would the Johansen procedure incorrectly reject the null of no cointegration? Table 3 reports evidence on this, by showing the fraction of simulations for which Johansen's bootstrapped trace statistic incorrectly rejects the null of no cointegration at a given significance level, based on taking the estimated structural VARs as the DGPs. As the tables shows, Johansen's procedure tends to spuriously detect cointegration a non-negligible fraction of the times. Taking the estimated Bayesian structural VARs featuring four permanent inflation shocks as DGPs, for example, for the Euro area and the U.K., the fractions of bootstrapped $p$-values for Johansen's trace statistic for testing the null of no cointegration between 
inflation and the unemployment rate which are smaller than 10 per cent are equal to 26.9 and 23.6 per cent respectively. This means that the trace test would incorrectly reject the null of no cointegration between inflation and unemployment at the 10 per cent level about one-fourth of the times. As for the trace test of cointegration between inflation, unemployment, and the short rate, the fraction of bootstrapped $p$ values smaller than 10 per cent range between 45.4 and 72.1 per cent, thus essentially pointing towards the unreliability of such tests conditional on these DGPs. Results based on taking Bayesian VARs featuring a single permanent inflation shock as the DGP are in line with those discussed so far for the trace test of cointegration between inflation, unemployment, and the short rate, and are instead significantly better for the test of cointegration between inflation and unemployment.

Overall, these results suggest that evidence such as that reported in Table 2 should be discounted, as these results might as well be due to the limitations of cointegration tests conditional on these specific DGPs.

\subsubsection{The adjustment dynamics implied by the estimated loading vectors}

Even ignoring the results reported in Table 3, the evidence shown in the last two columns of Figure 1 is however hardly compatible with the notion of an exploitable long-run Phillips trade-off, that is, a trade-off which a policymaker might be able to purposefully use in order to permanently decrease the unemployment rate by engineering a higher equilibrium inflation rate. As pointed out by Evans (1994, p. 222) in his comment on King and Watson (1994),

'[... for a trade-off to be viewed as exploitable, a decision-maker must have confidence that unemployment can be reduced by engineering a higher rate of inflation [...] It would be of little comfort to many politicians if the Phillips curve trade-off simply implied that if unemployment instead turned higher, at least inflation would be lower.'

The bootstrapped distributions of the estimates of the elements of the loading vector of the error-correction term in the VECM reported in Figure 1, however, clearly point towards the latter case, with the estimated loading on the first difference of the unemployment rate being extremely small for either country, and, in the case of the Euro area, being insignificantly different from zero at conventional levels (for the U.K., on the other hand, it is statistically significant at the 10 per cent level, but not at the 5 per cent level). This implies that, following a shock to the common stochastic trend, the bulk of the dynamic adjustment to disequilibrium takes place through movements in inflation, rather than via movements in the unemployment rate. This is difficult to reconcile with the notion of an exploitable Phillips trade-off, and might instead be compatible (e.g.) with the notion that, in either country, policymakers engineered sharp recessions in order to put an end to the Great Inflation. In turn, 
such recessions caused permanent increases in the unemployment rate via hysteresis effects, and inflation came down gradually.

Let us now turn to the evidence produced by non-cointegrated structural VARs featuring a single permanent inflation shock.

\subsection{Evidence from non-cointegrated SVARs featuring a sin- gle permanent inflation shock}

We start by considering either Classical or Bayesian VARs featuring a single permanent inflation shock. For either country we estimate the $\operatorname{VAR}(p)$ model

$$
Y_{t}=B_{0}+B_{1} Y_{t-1}+\ldots+B_{p} Y_{t-p}+u_{t}, \quad E\left[u_{t} u_{t}^{\prime}\right]=\Omega
$$

where $Y_{t} \equiv\left[y_{t}, \Delta \pi_{t}, \Delta U_{t}, \Delta R_{t}, S_{t}\right]^{\prime}$ for the Euro area, Canada, and Australia, and $Y_{t} \equiv\left[y_{t}, \Delta \pi_{t}, \Delta U_{t}, R_{t}, C Y_{t}, S_{t}\right]^{\prime}$ for the U.K., with $y_{t}, \pi_{t}, U_{t}, R_{t}, C Y_{t}$, and $S_{t}$ being the output gap, inflation, the unemployment rate, the short rate, the consumption/GDP ratio, and the long-short spread, respectively. These variables effectively expand the informational content of King and Watson's original bivariate VAR along several dimensions. The short rate and, to a lesser extent, the long-short spread contain information about the monetary policy stance. As recently shown by Kurmann and Otrok (2013), the long-short spread possesses a strong informational content for future movements in technology. Finally, the consumption/GDP ratio and the output gap estimate can be regarded as two 'noisy estimates' of the state of the business cycle (as for the consumption/GDP ratio, see Cochrane's (1994) extensive discussion on this).

The U.S. is the only country for which Johansen's trace test produces evidence of cointegration between the short rate and inflation (see Table 2), with the bootstrapped, bias-corrected estimate of the second element of the cointegrating vector being equal to -1.018 , and with a $p$-value of 0.423 for rejecting the null hypothesis that it is equal to -1. For the U.S. I therefore set $Y_{t} \equiv\left[y_{t}, \Delta \pi_{t}, \Delta U_{t}, C R_{t}, R_{t}-\pi_{t}, S_{t}\right]^{\prime}$, where $R_{t}-\pi_{t}$ is the ex post real rate. For the Euro area, Canada, and the U.K. I set the lag order to $p=4$. For the U.S., for which I work at the monthly frequency, I set it to $p=12$. I identify the permanent inflation shock based on the restriction that it is the only shock impacting upon inflation in the infinite long run. This is tantamount to imposing that in the second row of the long-run impact matrix $C_{\infty} \equiv\left[I_{N}-B(1)\right]^{-1} A_{0}$, where $A_{0}$ is the structural shocks' impact matrix, all of the elements except the first one are equal to zero, so that the first element of $\epsilon_{t}=A_{0}^{-1} u_{t}$ is the permanent inflation shock. $^{11}$

\footnotetext{
${ }^{11}$ Roberts (1993) estimated a VAR for the U.S. for the first differences of inflation and the unemployment rate, and the logarithm of $M_{2}$ velocity, and identified two permanent shocks to inflation and the unemployment rate, respectively, by imposing the restrictions that they are the only shocks impacting either variable in the long run. A key difference between Roberts (1993) and the present work is that he imposed orthogonality between the two shocks (that is, he imposed a vertical long-
} 


\subsubsection{Classical estimation}

Working within a Classical context, I estimate (1) via OLS based on the standard formulas found in Luetkepohl (1991). Concerning the estimation of the impact matrix of the structural shocks, as extensively discussed by Christiano et al. (2006), reliably estimating $C_{\infty}$ requires a good estimate of the spectral density of $Y_{t}$ at the frequency $\omega=0, S_{Y}(0)=C_{\infty} C_{\infty}^{\prime}$, an object which VARs, given their focus on fitting the shortrun dynamics of the data, should not necessarily be expected to capture well. Following Christiano et al. (2006) we therefore consider, beyond the standard estimator of $S_{Y}(0)$ produced by the VAR - that is, $\hat{S}_{Y}^{V A R}(0)=\left[I_{N}-\hat{B}(1)\right]^{-1} \hat{V}\left\{\left[I_{N}-\hat{B}(1)\right]^{-1}\right\}^{\prime}$, where $\hat{V}$ is the estimated covariance matrix of the VAR's reduced-form innovationsthe estimator produced by the Bartlett estimate of the spectral density matrix (see Hamilton (1994)).

We use standard bootstrapping techniques in order to both bias-correct the estimated long-run impacts of the permanent inflation shock as in Kilian (1998), and characterise the extent of uncertainty around the bias-corrected estimates (so, to be clear, the only difference between Kilian's (1998) paper and the present work is that he dealt with the bias-correction of IRFs, whereas we are here bias-correcting the long-run impacts of the structural shocks). Specifically, we bootstrap the estimated reduced-form VAR 10,000 times, and based on each bootstrap replication we estimate a $\operatorname{VAR}(p)$; we impose the same identification scheme we imposed on the VAR estimated based on the actual data; and we compute the implied long-run impact on the unemployment rate of the permanent inflation shock. Then, we use such bootstrapped distributions, first, to bias-correct the simple estimate of the long-run impact; and second, to characterise the extent of uncertainty surrounding such biascorrected estimates, by simply rescaling the original bootstrapped distribution in such a way that its median be equal to the bias-corrected estimate (in general, however, the extent of the bias is very small, so that, in the end, bias-correcting does not make a material difference to the results).

\subsubsection{Bayesian estimation}

Working within a Bayesian context, we estimate (1) as in Uhlig (1998, 2005). Specifically, we exactly follow Uhlig $(1998,2005)$ in terms of both distributional assumptionsthe distributions for the VAR's coefficients and their covariance matrix are postulated to belong to the Normal-Wishart family - and of priors. For estimation details the reader is therefore referred to either the Appendix of Uhlig (1998), or to Appendix B of Uhlig (2005). Finally, for each estimated VAR we consider 10,000 draws from the posterior distribution of the VAR's coefficients and covariance matrix of innovations (the draws are computed exactly as in Uhlig $(1998,2005)$ ).

run Phillips curve). See also Bullard and Keating (1995), who, working with bivariate VARs for the first difference of inflation and either output growth, or its first difference, use the same restriction used herein in order to identify permanent inflation shocks. 


\subsubsection{Evidence}

Since, for either country, results are very close both across econometric methodologies (Classical versus Bayesian) and, within the Classical approach, for the two alternative estimators of the spectral density matrix of the VAR at $\omega=0$, in what follows we only report and discuss those produced by the Bayesian approach. The online appendix however reports the entire set of results (see Figure A.3, and Table A.3).

Figure 2 shows, for either country, the distribution of the long-run impacts on the unemployment rate of a one per cent permanent shock to inflation, together with the distribution of the fraction of the permanent component of unemployment which is explained by the permanent inflation shock. Table 4 reports the median and the $90 \%$ coverage percentiles of the distribution of the long-run impact on the unemployment rate of a one per cent permanent shock to inflation, together with the fractions of the mass of the distribution for which the impact is estimated to be negative.

Results are uniformly consistent across countries, and for neither of them do they allow to reject the 'natural' null hypothesis of a vertical long-run Phillips curve. In particular, for either country the 90 per cent confidence interval for the estimated long-run impact on unemployment of a permanent inflation shock contains zero, and the fraction of the mass of the posterior distribution for which the impact is estimated to be negative is uniformly greater than standard levels of statistical significance, thus highlighting how the null hypothesis of a vertical long-run Phillips curve cannot be rejected at conventional levels. Further, for either country the posterior distribution of the fraction of the permanent component of the unemployment rate which is explained by permanent inflation shocks is clustered towards zero, thus implying that such shocks explain very little of the unit root component of unemployment, and providing additional evidence in support of the notion that the long-run Phillips curve is indeed vertical. $^{12}$

A researcher looking for evidence of a negative long-run trade-off may find some limited support from the results for the U.S. and Canada, for which the fraction of draws from the posterior for which the long-run impact is estimated to be negative is slightly above 80 per cent. Although far from standard levels of statistical significance, still, this provides some support to the notion of a negative long-run trade-off. Further, the median estimate of the long-run impact for the U.S., at -0.27, implies that a permanent increase in inflation by 10 percentage points would permanently decrease the unemployment rate by 2.7 per cent, a non-negligible amount. It is fair to say, however, that the overall picture emerging from Table 2 and Figure 2 (and from Table A.2 and Figure A.2) points towards no long-run trade-off. For the other four countries, for example, the median estimates of the permanent decrease in the unemployment rate associated with a permanent increase in inflation by 10 percent-

\footnotetext{
${ }^{12}$ By definition, a vertical long-run Phillips curve implies that the fraction of the permanent component of the unemployment rate which is explained by the permanent inflation shock is equal to zero.
} 
age points range between -0.4 and -1.3 per cent. Even if we were willing to believe that the median estimates capture the authentic unemployment-inflation trade-offs out there, these are hardly trade-offs which might induce policymakers to 'try to play the Phillips curve'.

\subsection{Evidence on monetary policy shocks from non-cointegrated SVARs featuring four permanent inflation shock}

Since, in principle, the results discussed in the previous section are not incompatible with the notion that some of the shocks exerting a permanent impact on inflation may induce a non-vertical long-run Phillips trade-off, working within a Bayesian context we then proceed to disentangle permanent inflation shocks into demand- and supply-side ones, by imposing Canova and Paustian's (2011) DSGE-based 'robust sign restrictions' on their impact on the endogenous variables at $t=0 .{ }^{13}$ As we will discuss, even doing this it is not possible to find any evidence that there exists at least one type of shock which may induce a non-vertical long-run Phillips trade-off.

\subsubsection{Identification}

Our identification strategy is based on the combination of long-run and sign restrictions. We start by separating the VAR's structural shocks into two sets, depending on the fact that they do, or they do not have a permanent impact on inflation. Let the structural $\operatorname{VAR}(p)$ model be given by

$$
Y_{t}=B_{0}+B_{1} Y_{t-1}+\ldots+B_{p} Y_{t-p}+A_{0} \epsilon_{t}
$$

where $Y_{t}$ defined as before; $A_{0}$ being the impact matrix of the structural shocks at $t=$ 0 ; and $\epsilon_{t} \equiv\left[\epsilon_{t}^{T E}, \epsilon_{t}^{M O}, \epsilon_{t}^{T A}, \epsilon_{t}^{M K}, \epsilon_{t}^{T R \prime}\right]^{\prime}$ being the structural shocks, which, as standard practice, are assumed to be unit-variance and orthogonal to one another, with $\epsilon_{t}^{T E}$, $\epsilon_{t}^{M O}, \epsilon_{t}^{T A}, \epsilon_{t}^{M K}$ being Canova and Paustian's (2011) 'technology', 'monetary policy', 'taste', and 'markup' shocks (to be discussed shortly), which are here allowed to exert a permanent impact on inflation, and $\epsilon_{t}^{T R}$ being instead a $2 \times 1$ vector of shocks which, by construction, have a transitory impact on inflation. The second row of the matrix of long-run impacts of the structural shocks, $\left[I_{N}-B(1)\right]^{-1} A_{0}$-i.e., the row corresponding to inflation - is therefore postulated to have the following structure,

$$
\text { Long-run impacts of the structural shocks on } \pi_{t}:\left[\begin{array}{ccccc}
\epsilon_{t}^{T E} & \epsilon_{t}^{M O} & \epsilon_{t}^{T A} & \epsilon_{t}^{M K} & \epsilon_{t}^{T R \prime} \\
x & x & x & x & 0 \\
& x & 0
\end{array}\right]
$$

\footnotetext{
${ }^{13}$ A subtle but important point here is the following. Since Canova and Paustian's 'robust sign restrictions' have originally been derived based on a New Keynesian model log-linearized around a zero-inflation steady-state, and in which inflation is stationary, it is in principle an open question whether such restrictions would also hold in the case in which, within the same model, inflation has a unit root. In fact, this is indeed the case, with the results for the case in which inflation is I(1) being numerically very close to the 'benchmark' results one obtains based on the specification reported in their Table 1 (all of these results are available upon request).
} 
- where a ' 0 ' means that the corresponding long-run impact has been restricted to zero, whereas an ' $x$ ' means that it has been left unrestricted - thus implying that $\epsilon_{t}^{T E}$, $\epsilon_{t}^{M O}, \epsilon_{t}^{T A}$, and $\epsilon_{t}^{M K}$ may have a permanent impact on inflation, whereas $\epsilon_{t}^{T R}$ does not. The restriction that the two shocks in $\epsilon_{t}^{T R}$ are the only shocks which do not have a permanent impact on inflation is sufficient to disentangle them from the other four shocks. As for separating $\epsilon_{t}^{T E}, \epsilon_{t}^{M O}, \epsilon_{t}^{T A}$, and $\epsilon_{t}^{M K}$ from one another, I achieve that by imposing the following set of sign restrictions on impact:

\begin{tabular}{||r|cccc||}
\hline \hline & \multicolumn{4}{|c||}{ Shock: } \\
\hline Variable: & $\epsilon_{t}^{T E}$ & $\epsilon_{t}^{M O}$ & $\epsilon_{t}^{T A}$ & $\epsilon_{t}^{M K}$ \\
\hline Output gap & + & - & + & - \\
Inflation & - & - & + & + \\
Unemployment rate & + & + & - & + \\
Short rate & - & + & + & + \\
\hline \hline
\end{tabular}

where ' + ' means 'greater than, or equal to zero', and '-' means 'smaller than, or equal to zero'. In words, a technology shock causes the output gap and the unemployment rate not to decrease, and inflation and the short rate not to increase; a monetary shock causes the output gap and inflation not to increase, and unemployment and the short rate not to decrease; a taste shock causes unemployment not to increase, and all other variables not to decrease; and a markup shock causes the output gap not to increase, and all other variables not to decrease. These restrictions are the same as the 'robust sign restrictions' reported by Canova and Paustian (2011) in their Table 2 for their benchmark DSGE model featuring sticky prices, sticky wages, and several standard frictions (see the column labelled there as ' $\mathrm{M}$ '), with the only obvious difference that, since their model features employment, instead of the unemployment rate, the signs I am here imposing on the unemployment rate are the opposite of those reported by Canova and Paustian for employment.

In what follows I impose these sign restrictions only on impact. The reason for doing this is that, as stressed by Canova and Paustian (2011), whereas sign restrictions on impact are, in general, robust - in the specific sense that they hold for the vast majority of sub-classes within a specific class of DSGE models, and for the vast majority of plausible parameters' configurations - restrictions at longer horizons are instead, as they put it, 'whimsical', meaning that they are hard to pin down, and in general, they are not robust across sub-classes of models, and for alternative plausible parameters' configurations. ${ }^{14}$ It is to be noticed that Canova and Paustian (2011)

\footnotetext{
${ }^{14}$ One obvious limitation of imposing the sign restrictions only on impact is that we are here using a comparatively limited amount of information in order to achieve identification. As a consequence, our results necessarily end up being less sharp than they could have been had we been reasonably confident about imposing a specific pattern of sign restrictions at horizons greater than zero. This compounds a well-known limitation of sign restrictions which has been extensively discussed by Fry and Pagan (2011): as these authors stress, sign restrictions are intrinsically 'weak information', since they are based on the notion of uniquely imposing a specific pattern of signs on the IRFs.
} 
reached this conclusion based on a quarterly DSGE model. Since for the U.S. I am here working at the monthly frequency, for reasons of consistency I impose the sign restrictions both on impact, and for the two months after the impact.

\subsubsection{Computing the structural impact matrix $A_{0}$}

For each draw from the posterior distribution of the VAR's reduced-form parameters we compute the structural impact matrix, $A_{0}$, via the methodology proposed by Arias, Rubio-Ramirez, and Waggoner (2014) for combining zero and sign restrictons. Specifically, let $B_{0}^{n}, B_{1}^{n}, \ldots, B_{p}^{n}$, and $\Omega^{n}$ be the $n$-th draw from the posterior distribution for the intercept, the VAR matrices, and the covariance matrix of reduced-form innovations of the VAR (1), for $n=1,2,3, \ldots, N$. Let $P_{n} D_{n} P_{n}^{\prime}$ be the eigenvalue-eigenvector decomposition of $\Omega^{n}$. We start by computing an initial estimate of $A_{0}^{n}$-let's call it $\tilde{A}_{0}^{n}$-as $\tilde{A}_{0}^{n}=P_{n} D_{n}^{\frac{1}{2}}$ with the corresponding matrix of long-run impacts of the structural shocks $\tilde{L}_{n}=\left[I_{K}-B^{n}(1)\right]^{-1} \tilde{A}_{0}^{n}$, where $K$ is the number of series in the VAR, and $B^{n}(1)=B_{1}^{n}+B_{2}^{n}+\ldots+B_{p}^{n}$. Based on the Gibbs-sampling algorithm described in section 3.6.3 of Arias et al. (2014), we then draw $Z$ random orthonormal matrices of dimension $K \times K$ from the uniform distribution, conditional on the zero restrictions on the long-run impacts of the structural shocks on inflation shown in (3) - that is: four shocks are allowed to have a non-zero long-run impact on inflation, whereas the remaining two shocks are forced to have no long-run impact. Let $Q_{z}^{n}, z=1,2,3, \ldots$, $Z$, be the $z$-th random orthonormal matrix, with $Q_{z}^{n}\left(Q_{z}^{n}\right)^{\prime}=I_{K}$. We then combine each of the $Z$ random orthonormal matrices with the initial estimate of the long-run impact of the structural shocks, $\tilde{L}_{n}$, in order to obtain a randomly rotated long-run impact matrix, $L_{n}^{z}=\tilde{L}_{n} Q_{z}^{n}$. By construction, each $L_{n}^{z}, z=1,2,3, \ldots, Z$, satisfies the zero long-run restrictions in (3). From $L_{n}^{z}$ we then obtain the corresponding candidate estimate of the structural impact matrix, $A_{0, n}^{z}=\left[I_{K}-B^{n}(1)\right] L_{n}^{z}$. Finally, we check whether $A_{0, n}^{z}$ satisfies the sign restrictions reported in the table in Section 4.3.1, and out of the $Z$ candidate structural impact matrices we only keep, for draw $n$, those satisfying the sign restrictions. For each draw from the posterior we consider 10,000 random rotation matrices. Finally, we set the number of Gibbs-sampling iterations in the algorithm to $L=5 .^{15}$

The rationale behind our decision of imposing sign restrictions only on impact is that it is better to impose a limited amount of information about which we can be reasonably confident than a greater amount of information about which we have limited confidence.

${ }^{15}$ As pointed out by Arias et al. (2014, p. 18), '[t]here is also the question of how large L should be to obtain convergence. Experiments show that for the starting value given below, even $L=1$ gives a good approximation of the desired distribution. In practice, increasing values of $L$ can be used to determine when convergence has occurred.' My experience with the algorithm confirms this. Although I set $L=5$, convergence was typically achieved at most at the second iteration. 


\subsubsection{Evidence}

Figures 3-5 and Table 5 show the results for monetary shocks, whereas Figures A.4-A.6 and Tables A.4-A.6 in the online appendix report the full set of results for all the four shocks which are here allowed to have a permanent impact on inflation. The reason for narrowly focusing on monetary shocks is that the motivation behind all explorations of the slope of the long-run Phillips trade-off has always been understanding whether the monetary authority might be able to permanently lower the unemployment rate by engineering a permanently higher rate of inflation. Under this respect, the long-run Phillips trade-offs which might originate from permanent inflation shocks of a nonmonetary nature are therefore irrelevant. It is to be stressed, however, that results for the other three permanent inflation shocks are qualitatively the same as those for monetary shocks, and clearly suggest that, even 'digging' into the permanent inflation shock identified in Section 4.2, it is not possible to find any evidence that at least some shocks may generate a non-vertical trade-off.

Figure 3 shows, for either country, the posterior distribution of the long-run impact on the unemployment rate of a monetary shock having a one per cent permanent impact on inflation, whereas Figures 4 and 5 show the posterior distributions of the fractions of the permanent components of inflation and the unemployment rate, respectively, explained by monetary shocks. Table 5 reports the the median and the $90 \%$-coverage percentiles of the posterior distribution of the long-run impact of monetary shocks on unemployment; the fraction of draws for which the impact is estimated to be negative; and the medians and the $90 \%$-coverage percentiles of the posterior distributions of the fractions of the permanent components of inflation and unemployment explained by monetary shocks. Finally, Tables A.5 and A.6 in the online appendix also report the fractions of the mass of the posterior distributions of the fractions of the permanent components of inflation and unemployment explained by monetary shocks which are below three selected 'cut-off points', 0.1, 0.05, and 0.01, thus providing a numerical measure of how strongly clustered towards zero such distributions are.

Overall, results for monetary shocks are in line with those for the 'aggregate' permanent inflation shocks discussed in Section 4.2, and in no way provide strong support to the notion that the monetay authority might be able to permanently reduce the unemployment rate by 'playing the Phillips curve game'. Once again, the fractions of the mass of the posterior distribution for which the impact is estimated to be negative, ranging between 0.480 for the Euro area and 0.836 for Canada, are uniformly greater than standard levels of statistical significance, and for either country the 90 per cent confidence interval for the estimated long-run impact of a monetary shock on unemployment contains zero. Finally, for either country monetary shocks are estimated to have accounted for very small fractions of the unit root component of the unemployment rate.

Once again, however, the extent of uncertainty associated with the estimated long-run trade-offs is uniformly substantial, so that these results are, in fact, compat- 
ible with a comparatively wide range of possible slopes. This means that, although we regard the null hypothesis of a vertical long-run trade-off as the natural one, a researcher with a different view of the world, and therefore different priors about what the natural benchmark should be, might not see her views about the slope of the long-run Phillips curve falsified. This originates from the fact that the feature of the data we are here estimating pertains to the infinite long-run, and, as it is well known - see, first and foremost, Faust and Leeper (1997) - this inevitably produces imprecise estimates, unless the researcher is willing to impose upon the data very strong informational assumptions. Within the present context, this problem is compounded by our use of sign restrictions, which, as stressed by Fry and Pagan (2011), are intrinsically 'weak information', and should therefore not be expected to produce strong inference.

\section{Conclusions}

In this paper I have used structural VARs identified based on either long-run restrictions, or a combination of long-run and sign restrictions, to investigate the long-run trade-off between inflation and the unemployment rate in the U.S., the Euro area, the U.K., Canada and Australia over the post-WWII period. Results based on VARs featuring a single permanent inflation shock do not allow to reject the null hypothesis of a vertical long-run Phillips curve for either country. Results based on VARs allowing for four permanent inflation shocks, which are sorted out from one another by means of DSGE-based robust sign restrictions, produce a very similar picture. The overall extent of uncertainty is however substantial, thus suggesting that the data are compatible with a comparatively wide range of possible slopes of the long-run trade-off. For all countries, Johansen's cointegration tests point towards the presence of cointegration between either inflation and unemployment, or inflation, unemployment, and a short-term interest rate, with the long-run Phillips trade-off implied by the estimated cointegrating vectors being negative and sizeable. I argue however that this evidence should be discounted, as, conditional on the estimated structural VARs - which, by construction, do not feature cointegration between any variable Johansen's procedure tends to spuriously detect cointegration a non-negligible, and sometimes large, fraction of the times. 


\section{References}

Akerlof, G., W. T. Dickens, and G. Perry (1996): "The Macroeconomics of Low Inflation", Brookings Papers on Economic Activity, 1996(1), 1-76.

Barsky, R. (1987): "The Fisher Hypothesis and the Forecastability and Persistence of Inflation", Journal of Monetary Economics, 19(1), 3-24.

Barsky, R., and E. Sims (2011): "News shocks and business cycles", Journal of Monetary Economics, 58(3), 273-289.

K. I. Beltrao and P. Bloomfield (1987): "Determining the Bandwidth of a Kernel Spectrum Estimate", Journal of Time Series Analysis, 8(1), 21-38.

Benati, L. (2008): "Investigating Inflation Persistence Across Monetary Regimes", Quarterly Journal of Economics, 123(3), 1005-1060.

Benigno, G., and L. A. Ricci (2011): "The Inflation-Output Trade-Off with Downward Wage Rigidities", American Economic Review, 101(4), 1436-66.

Bernanke, B., M. Gertler, and M. Watson (1997): "Systematic Monetary Policy and the Effects of Oil Price Shocks", Brookings Papers on Economic Activity, 1997(1), 91-157.

Bernanke, B. S., T. Laubach, F. S. Mishkin, and A. Posen (1999): Inflation Targeting: Lessons from the International Experience, Princeton University Press.

Bullard, J., and J. W. Keating (1995): "The Long-Run Relationship Between Inflation and Output in Postwar Economies", Journal of Monetary Economics, 36, 477-496.

Canova, F., and G. de Nicolo (2002): "Monetary disturbances matter for business fluctuations in the G-7", Journal of Monetary Economics, 49(6), 1131-1159.

Canova, F., and M. Paustian (2011): "Measurement with Some Theory: Using Sign Restrictions to Evaluate Business Cycle Models", Journal of Monetary Economics, 58, 345-361.

Canova, F., and J. Pina (2005): "What VAR Tell Us About DSGE Models", in Diebolt, C. and Kyrtsou, C., New Trends In Macroeconomics, Springer Verlag.

Carlstrom, C., T. Fuerst, and M. Paustian (2009): "Monetary Policy Shocks, Choleski Identification, and DNK Models", Journal of Monetary Economics, 56(7), 1014-1021.

Christiano, L. J., M. Eichenbaum, and R. Vigfusson (2006): "Assessing Structural VARS", in D. Acemoglu, K. Rogoff and M. Woodford, eds. (2007), NBER Macroeconomics Annuals 2006, Cambridge, The MIT Press.

Cochrane, J. H. (1994): "Permanent and Transitory Components of GNP and Stock Prices", Quarterly Journal of Economics, 109(1), 241-265.

Elliot, G., Rothenberg, T., and Stock, J.H. (1996): "Efficient Tests for an Autoregressive Unit Root", Econometrica, 64(4), 813-836

Evans, C. (1994): "Comment on: The Post-War U.S. Phillips Curve, A Revisionist Econometric History", Carnegie-Rochester Conference Series on Public Policy, 41, 221-230. 
Fama, E. (1975): "Short-Term Interest Rates as Predictors of Inflation", American Economic Review, 65(3), 269-282.

Faust, J. (1998): "The Robustness of Identified VAR Conclusions About Money", Carnegie-Rochester Conference Series on Public Policy, 49, 207-244.

Faust, J., and E. Leeper (1997): "When Do Long-Run Identifying Restrictions Give Reliable Results?", Journal of Business and Economic Statistics, 15(3), 345353.

Fernández-Villaverde, J., and J. F. Rubio-Ramírez (2008): "How Structural Are the Structural Parameters?", NBER Macroeconomics Annuals 200\%, Cambridge, The MIT Press, 83-137.

Fisher, M. E., and J. J. Seater (1993): "Long Run Neutrality and Superneutrality in an ARIMA Framework", American Economic Review, 83(3), 402-415.

Forni, M., and L. Gambetti (2014): "Testing for Sufficient Information in Structural VARs", Journal of Monetary Economics, 66(September), 124-136

Fry, R., and A. Pagan (2007): "Sign Restrictions in Structural Vector Autoregressions: A Critical Review", Journal of Economic Literature, 49(4), 938-60

Gregory, A.W., and B.E. Hansen (1996): "Tests for Cointegration in Models with Regime and Trend Shifts", Oxford Bulletin of Economics and Statistics, 58(3), 555$560 "$ "

Hamilton, J. (1994): Time Series Analysis, Princeton, N.J., Princeton University Press.

Hansen, B. (1999): "The Grid Bootstrap and the Autoregressive Model", Review of Economics and Statistics, 81(4), 594-607.

Kilian, L. (1998): "Small-Sample Confidence Intervals for Impulse-Response Functions", Review of Economics and Statistics, pp. 218-230.

King, R., and M. Watson (1994): "The Post-War U.S. Phillips Curve: A Revisionist Econometric History", Carnegie-Rochester Conference Series on Public Policy, 41, 157-219.

Kurmann, A., and C. Otrok (2013): "News Shocks and the Slope of the Term Structure of Interest Rates", American Economic Review, 103(6), 2612-32

Lucas, R. E. (1972a): "Econometric Testing of the Natural Rate Hypothesis", in Eckstein, O., ed., The Econometrics of Price Determination, Washington, D.C., Board of Governors of the Federal Reserve System, pp. 50-59.

Lucas, R. E. (1972b): "Expectations and the Neutrality of Money", Journal of Economic Theory, 4(April 1972), 103-24.

Lucas, R. E. (1973): "Some International Evidence on Output-Inflation TradeOffs", American Economic Review, 63(3), 326-334.

Lucas, R. E. (1976): "Econometric Policy Evaluation: A Critique", CarnegieRochester Conference Series on Public Policy, 1, 19-46.

Luetkepohl, H. (1991): Introduction to Multiple Time Series Analysis, II edition. Springer-Verlag. 
Pybus, T. (2011): "Estimating the UK's Historical Output Gap", Office for Budget Responsibility Working paper No. 1, November 2011.

Roberts, J. M. (1993): "The Sources of Business Cycles: A Monetarist Interpretation", International Economic Review, 34(4), 923-934.

Rubio-Ramirez, J., D. Waggoner, and T. Zha (2005): "Structural Vector Autoregressions: Theory of Identification and Algorithms for Inference", Review of Economic Studies, 77(2), 665-696.

Sargent, T. J. (1971): "A Note on the Accelerationist Controversy", Journal of Money, Credit and Banking, 3(3), 721-725.

Sargent, T. J. (1987): Macroeconomic Theory, II Edition. Orlando, Academic Press.

Solow, R. (1968): "Recent Controversy on the Theory of Inflation: An Eclectic View", in Proceedings of a Symposium on Inflation: Its Causes, Consequences, and Control, S. Rousseaus (ed.), New York: New York University.

Stock, J. H., and M.W. Watson (2007): "Why Has U.S. Inflation Become Harder to Forecast?", Journal of Money, Credit, and Banking, 39(1), 3-33.

Svensson, Lars E O. (2015): "The Possible Unemployment Cost of Average Inflation below a Credible Target", American Economic Journal: Macroeconomics, 7(1): 258-96.

Tobin, J. (1968): "Discussion", in Proceedings of a Symposium on Inflation: Its Causes, Consequences, and Control, S. Rousseaus (ed.), New York: New York University.

Uhlig, H. (1998): "Comment On: The Robustness of Identified VAR Conclusions About Money", Carnegie-Rochester Conference Series on Public Policy, 49, 245-263.

Uhlig, H. (2005): "What are the Effects of Monetary Policy on Output? Results from an Agnostic Identification Procedure", Journal of Monetary Economics, 52(2), $381-419$. 


\begin{tabular}{|c|c|c|c|c|c|c|c|c|}
\hline & \multicolumn{4}{|c|}{ CPI inflation } & \multicolumn{4}{|c|}{ GDP deflator inflation } \\
\hline & $p=2$ & $p=4$ & $p=6$ & $p=8$ & $p=2$ & $p=4$ & $p=6$ & $p=8$ \\
\hline \multicolumn{9}{|l|}{ United States $^{b}$} \\
\hline full sample (Jan. 1959-Jun. 2010) & 0.263 & 0.365 & 0.363 & 0.328 & 0.039 & 0.379 & 0.284 & 0.255 \\
\hline pre-Volcker (Jan. 1959-Jul. 1979) & 0.602 & 0.562 & 0.517 & 0.507 & 0.414 & 0.641 & 0.595 & 0.509 \\
\hline Volcker, Greenspan, and Bernanke & & & & & & & & \\
\hline (Aug. 1979-Jun. 2010) & 0.010 & 0.003 & 0.000 & 0.002 & 0.032 & 0.009 & 0.000 & 0.003 \\
\hline Euro area (1970Q1-1998Q4) & 0.752 & 0.744 & 0.845 & 0.869 & 0.557 & 0.786 & 0.908 & 0.927 \\
\hline Japan (1966Q4-2011Q4) & 0.075 & 0.069 & 0.331 & 0.303 & 0.040 & 0.1725 & 0.114 & 0.396 \\
\hline United Kingdom (1972Q1-1992Q3) & 0.234 & 0.245 & 0.401 & 0.528 & 0.177 & 0.283 & 0.567 & 0.312 \\
\hline Canada (1961Q1-1990Q4) & 0.134 & 0.226 & 0.351 & 0.194 & 0.160 & 0.246 & 0.250 & 0.222 \\
\hline Sweden (1970Q1-1992Q4) & 0.012 & 0.197 & 0.038 & 0.215 & - & - & - & - \\
\hline \multirow[t]{3}{*}{ Australia (1969Q3-1994Q2) } & 0.116 & 0.705 & 0.758 & 0.387 & 0.125 & 0.399 & 0.326 & 0.550 \\
\hline & \multicolumn{4}{|c|}{ Unemployment rate } & \multicolumn{4}{|c|}{ Short rate } \\
\hline & $p=2$ & $p=4$ & $p=6$ & $p=8$ & $p=2$ & $p=4$ & $p=6$ & $p=8$ \\
\hline \multicolumn{9}{|l|}{ United States $^{b}$} \\
\hline full sample (Jan. 1959-Jun. 2010) & 0.036 & 0.052 & 0.076 & 0.133 & 0.302 & 0.307 & 0.062 & 0.266 \\
\hline pre-Volcker (Jan. 1959-Jul. 1979) & 0.306 & 0.406 & 0.422 & 0.416 & 0.452 & 0.218 & 0.277 & 0.175 \\
\hline Volcker, Greenspan, and Bernanke & & & & & & & & \\
\hline (Aug. 1979-Jun. 2010) & 0.167 & 0.178 & 0.240 & 0.284 & 0.226 & 0.534 & 0.028 & 0.061 \\
\hline Euro area (1970Q1-1998Q4) & 0.363 & 0.270 & 0.256 & 0.433 & 0.371 & 0.425 & 0.606 & 0.680 \\
\hline Japan (1966Q4-2011Q4) & 0.618 & 0.616 & 0.495 & 0.537 & 0.282 & 0.333 & 0.460 & 0.561 \\
\hline United Kingdom (1972Q1-1992Q3) & 0.138 & 0.300 & 0.213 & 0.539 & 0.019 & 0.040 & 0.007 & 0.035 \\
\hline Canada (1961Q1-1990Q4) & 0.614 & 0.713 & 0.675 & 0.667 & 0.369 & 0.372 & 0.421 & 0.457 \\
\hline Sweden (1970Q1-1992Q4) & 0.265 & 0.303 & 0.300 & 0.263 & 0.440 & 0.299 & 0.383 & 0.537 \\
\hline Australia (1969Q3-1994Q2) & 0.748 & 0.560 & 0.618 & 0.389 & 0.313 & 0.310 & 0.333 & 0.439 \\
\hline
\end{tabular}




\begin{tabular}{|c|c|c|c|}
\hline \multirow[b]{3}{*}{ United States (January 1959-July 1979) } & \multicolumn{3}{|c|}{$\begin{array}{l}\text { Trace test of the null of } \\
\text { no cointegration between: }\end{array}$} \\
\hline & $\pi_{t}$ and $U_{t}$ & $\pi_{t}$ and $R_{t}$ & $\pi_{t}, U_{t}$ and $R_{t}$ \\
\hline & 0.190 & 0.007 & 0.001 \\
\hline Euro area (1970Q1-1998Q4) & 0.049 & 0.636 & 0.023 \\
\hline United Kingdom (1972Q1-1992Q3) & 0.017 & $\mathrm{NA}^{b}$ & $\mathrm{NA}^{b}$ \\
\hline Canada (1961Q1-1990Q4) & 0.200 & 0.209 & $7.0 \times 10^{-4}$ \\
\hline \multirow[t]{2}{*}{ Australia (1970Q1-1994Q2) } & 0.167 & 0.246 & 0.150 \\
\hline & \multicolumn{3}{|c|}{$\begin{array}{c}\text { Test of the null of one cointegrating } \\
\text { vector, versus the alternative } \\
\text { of two, for } \pi_{t}, U_{t} \text { and } R_{t} \text { : }\end{array}$} \\
\hline United States (January 1959-July 1979) & \multicolumn{3}{|c|}{0.073} \\
\hline Euro area (1970Q1-1998Q4) & \multicolumn{3}{|c|}{0.053} \\
\hline Canada (1961Q1-1990Q4) & \multicolumn{3}{|c|}{0.290} \\
\hline
\end{tabular}




\begin{tabular}{|c|c|c|c|c|c|}
\hline \multicolumn{6}{|c|}{$\begin{array}{l}\text { Table } 3 \text { Fraction of simulations for which Johansen's trace test incorrectly } \\
\text { rejects the null of no cointegration between inflation and unemployment } \\
\text { at a given significance level, based on estimated structural VARs }\end{array}$} \\
\hline & \multicolumn{3}{|c|}{$\begin{array}{l}\text { Based on structural } \\
\text { VARs with a single } \\
\text { permanent inflation shock }\end{array}$} & \multicolumn{2}{|c|}{$\begin{array}{l}\text { Based on structural } \\
\text { VARs with four } \\
\text { permanent inflation shocks }\end{array}$} \\
\hline & \multicolumn{5}{|c|}{$\begin{array}{l}\text { Fractions of bootstrapped } p \text {-values for } \\
\text { Johansen's trace statistic below: }\end{array}$} \\
\hline & 0.1 & 0.05 & 0.01 & $\begin{array}{ll}0.1 & 0.05\end{array}$ & 0.01 \\
\hline \multirow{4}{*}{$\begin{array}{l}\text { Euro area (1970Q1-1998Q4) } \\
\text { United Kingdom (1972Q1-1992Q3) }\end{array}$} & \multicolumn{5}{|c|}{ I: testing cointegration between $\pi_{t}$ and $U_{t}$} \\
\hline & 0.165 & 0.111 & 0.025 & $\begin{array}{ll}0.269 & 0.183\end{array}$ & 0.083 \\
\hline & 0.120 & 0.052 & 0.016 & $0.236 \quad 0.155$ & 0.060 \\
\hline & \multicolumn{5}{|c|}{ II: testing cointegration between $\pi_{t}, U_{t}$, and $R_{t}$} \\
\hline United States (January 1959-July 1979) & $\overline{0.653}$ & 0.527 & 0.202 & $\begin{array}{ll}0.721 & 0.605\end{array}$ & 0.256 \\
\hline Euro area (1970Q1-1998Q4) & 0.335 & 0.239 & 0.075 & 0.454 & 0.185 \\
\hline Canada (1961Q1-1990Q4) & 0.389 & 0.326 & 0.111 & 0.514 & 0.222 \\
\hline
\end{tabular}




\begin{tabular}{|c|c|c|}
\hline & $\begin{array}{l}\text { Long-run impact on } \\
U_{t} \text { of a permanent } \\
\text { shock to } \pi_{t}: a, b\end{array}$ & $\begin{array}{l}\text { Fraction of } \\
\text { draws for } \\
\text { which impact } \\
\text { is negative }\end{array}$ \\
\hline United States (January 1959-July 1979) & $-0.27[-0.95 ; 0.32]$ & 0.818 \\
\hline Euro area (1970Q1-1998Q4) & $-0.04[-0.78 ; 0.76]$ & 0.547 \\
\hline United Kingdom (1972Q1-1992Q3) & $-0.09[-0.50 ; 0.33]$ & 0.688 \\
\hline Canada (1961Q1-1990Q4) & $-0.13[-0.47 ; 0.17]$ & 0.805 \\
\hline Australia (1970Q1-1994Q2) & $-0.05[-0.24 ; 0.14]$ & 0.702 \\
\hline \multicolumn{3}{|c|}{$\begin{array}{l}{ }^{a} \text { Median, and } 90 \% \text {-coverage percentiles of the posterior distribution. } \\
{ }^{b} \text { Shocks are normalized so that they have a permanent impact on inflation } \\
\text { equal to } 1 \% \text {. }\end{array}$} \\
\hline
\end{tabular}




\begin{tabular}{|c|c|c|c|c|}
\hline & \multirow{2}{*}{$\begin{array}{l}\text { Long-run impact on } \\
U_{t} \text { of a permanent } \\
\text { monetary } \\
\text { shock to } \pi_{t}:{ }^{a, b}\end{array}$} & \multirow{2}{*}{$\begin{array}{l}\text { Fraction of } \\
\text { draws for } \\
\text { which impact } \\
\text { is negative }\end{array}$} & \multicolumn{2}{|c|}{$\begin{array}{l}\text { Fractions of permanent com- } \\
\text { ponents of } \pi_{t} \text { and } U_{t} \text { explained } \\
\text { by monetary shocks: }{ }^{a}\end{array}$} \\
\hline & & & $\pi_{t}$ & $U_{t}$ \\
\hline United States (January 1959-July 1979) & $-0.47[-3.59 ; 3.43]$ & 0.738 & $0.19[0.00 ; 0.79]$ & $0.24[0.00 ; 0.73]$ \\
\hline Euro area (1970Q1-1998Q4) & $0.02[-3.03 ; 2.52]$ & 0.480 & $0.12[0.00 ; 0.61]$ & $0.06[0.00 ; 0.38]$ \\
\hline United Kingdom (1972Q1-1992Q3) & $-0.21[-1.15 ; 0.68]$ & 0.819 & $0.32[0.01 ; 0.86]$ & $0.16[0.00 ; 0.63]$ \\
\hline Canada (1961Q1-1990Q4) & $-0.18[-0.73 ; 0.17]$ & 0.836 & $0.43[0.02 ; 0.89]$ & $0.11[0.00 ; 0.56]$ \\
\hline Australia (1970Q1-1994Q2) & $-0.04[-0.98 ; 0.73]$ & 0.586 & $0.15[0.00 ; 0.75]$ & $0.06[0.00 ; 0.52]$ \\
\hline
\end{tabular}


Ratio between the permanent impacts of the common shock on the unemployment rate and inflation
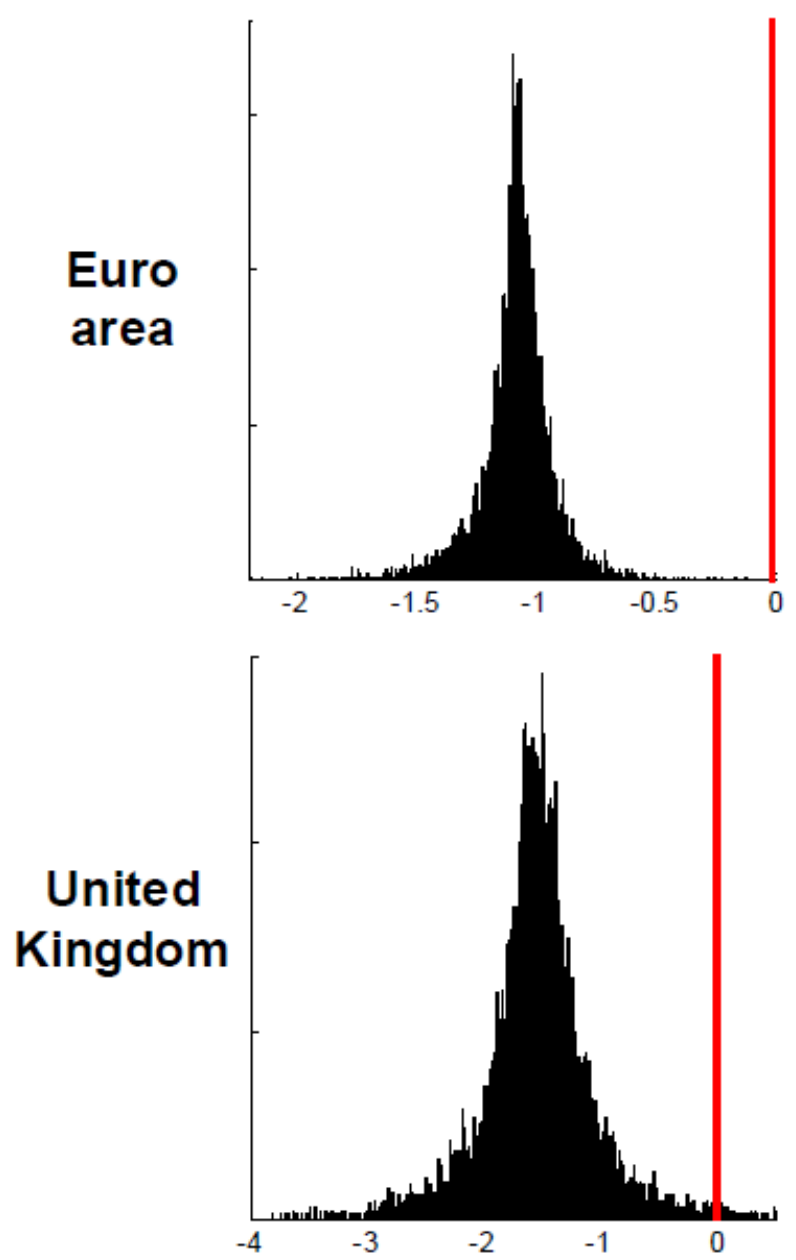

\section{Elements of the loading vector:}

Element on

Element on inflation unemployment
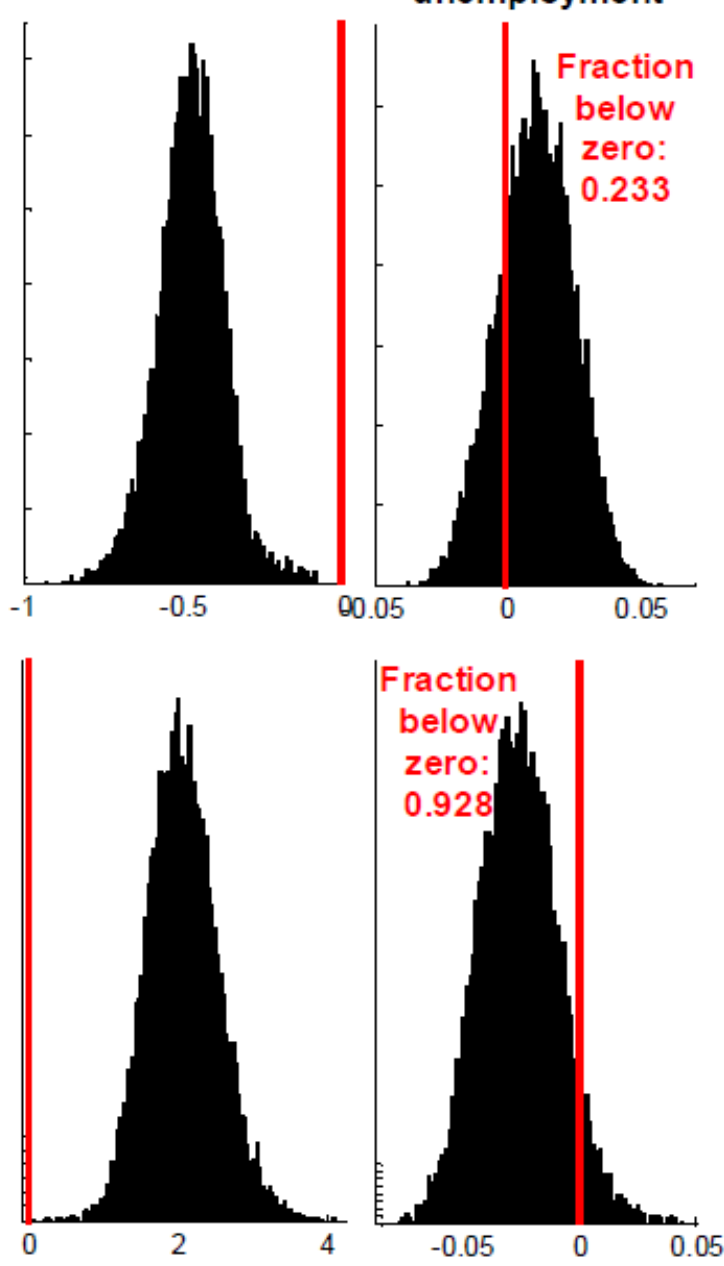

Figure 1 Bootstrapped distributions of the slope of the long-run Phillips curve implied by the estimated cointegrating vector between inflation and unemployment, and of the elements of the loadings vector 


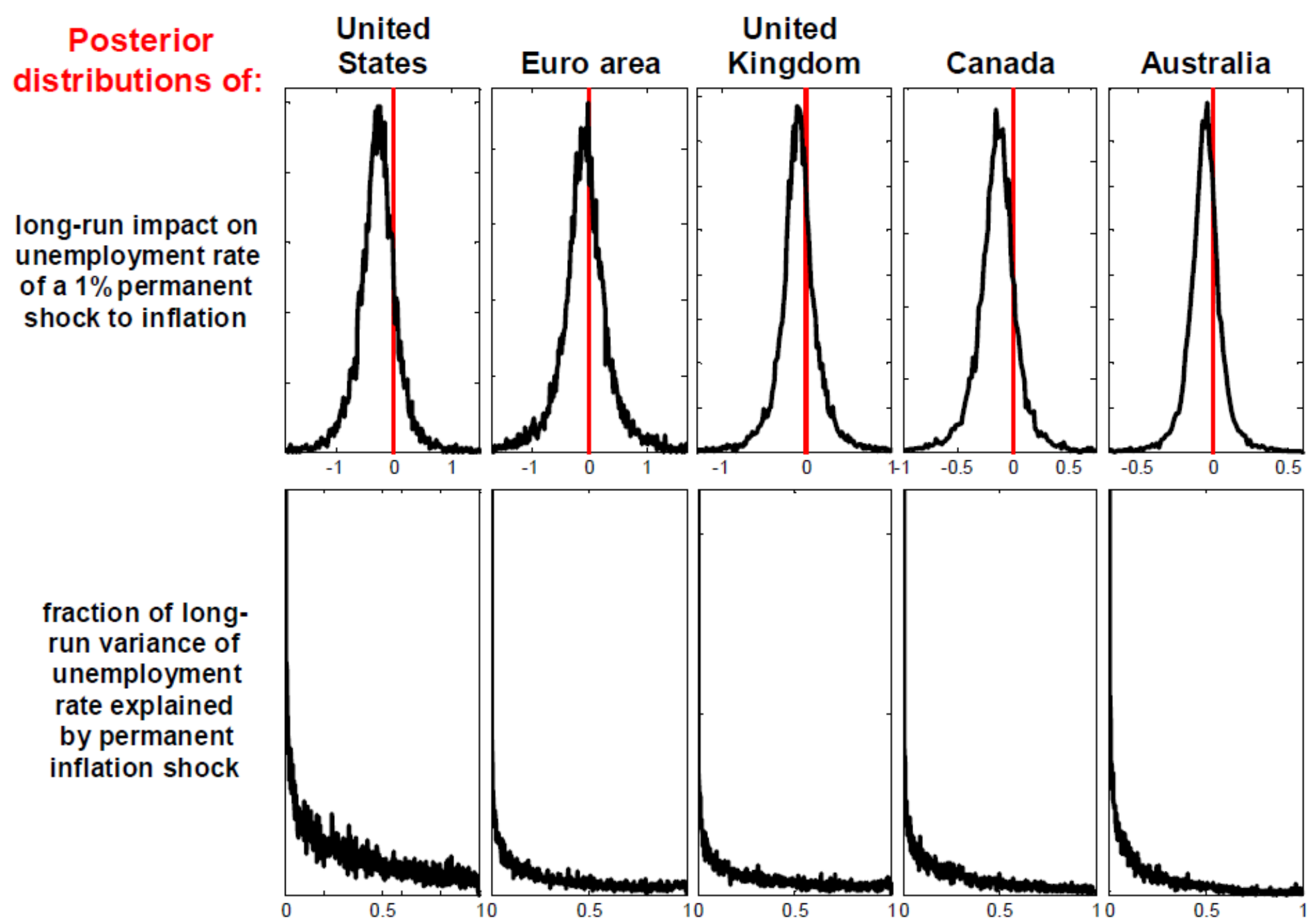

Figure 2 Results based on Bayesian VARs allowing for a single permanent inflation shock: posterior distributions of the long-run impact on the unemployment rate of a one per cent permanent shock to inflation; and of the fractions of the permanent component of unemployment explained by the permanent inflation shock 

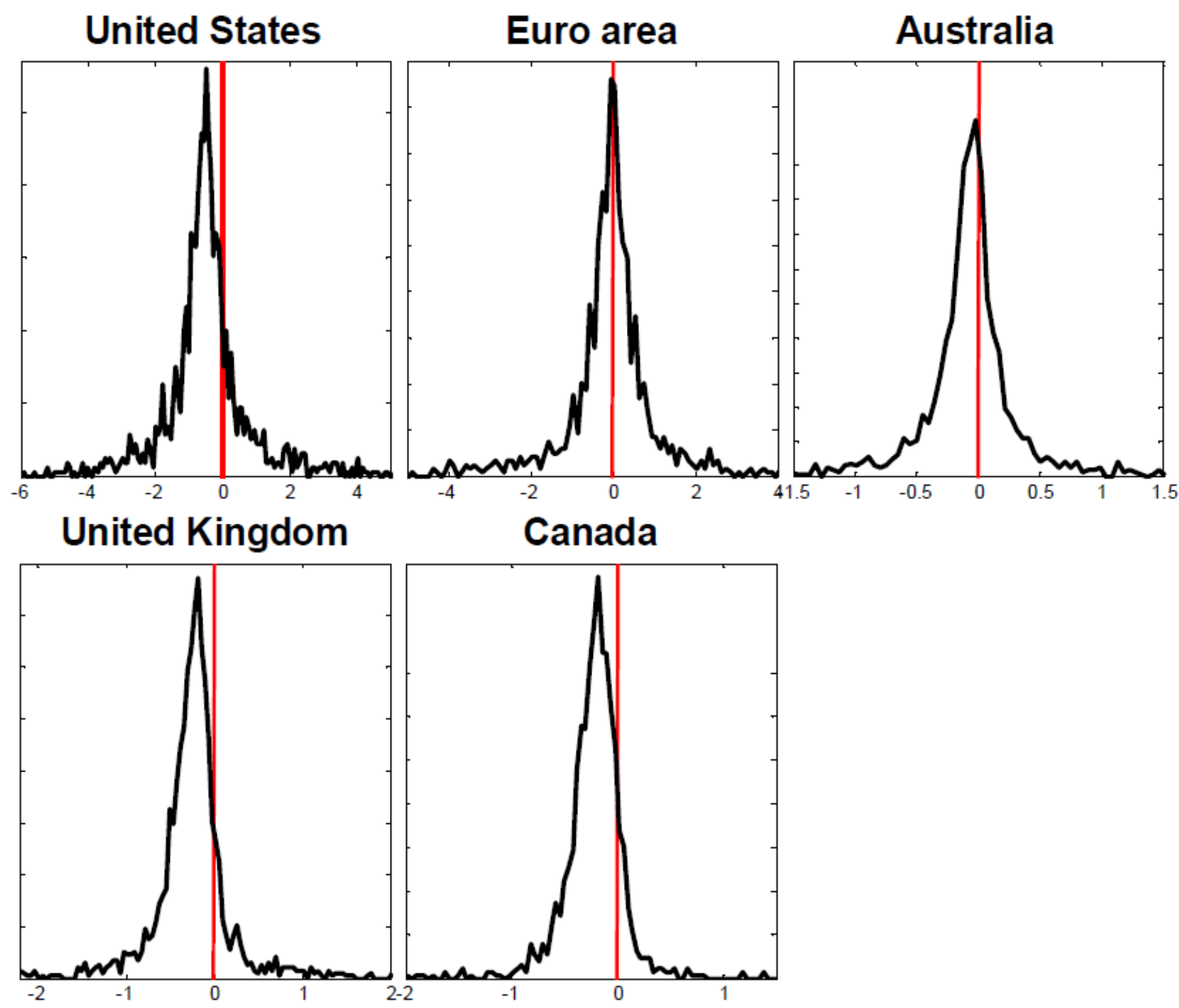

Figure 3 Results based on Bayesian VARs allowing for four permanent inflation shocks: posterior distribution of the long-run impact on the unemployment rate of a monetary shock having a one per cent permanent impact on inflation 

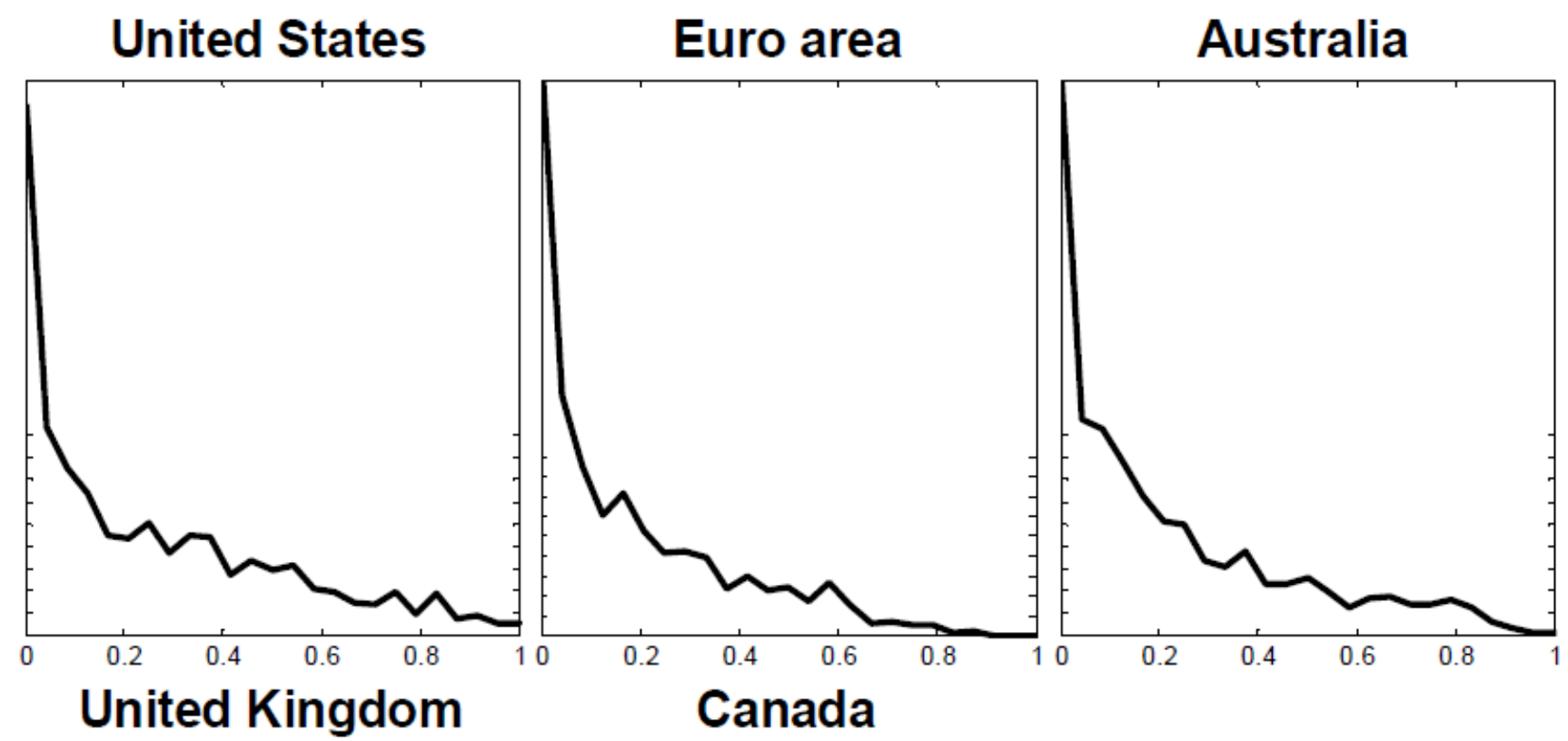

\section{Canada}

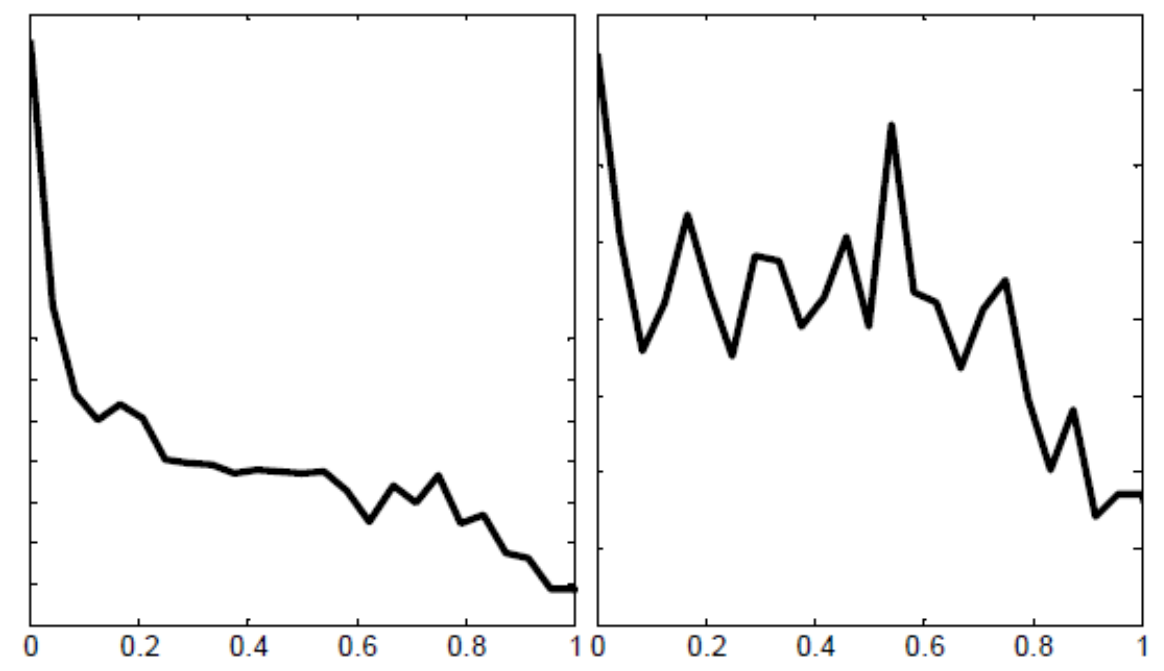

Figure 4 Results based on Bayesian VARs allowing for four permanent inflation shocks: posterior distribution of the fraction of the permanent component of inflation explained by monetary shocks 

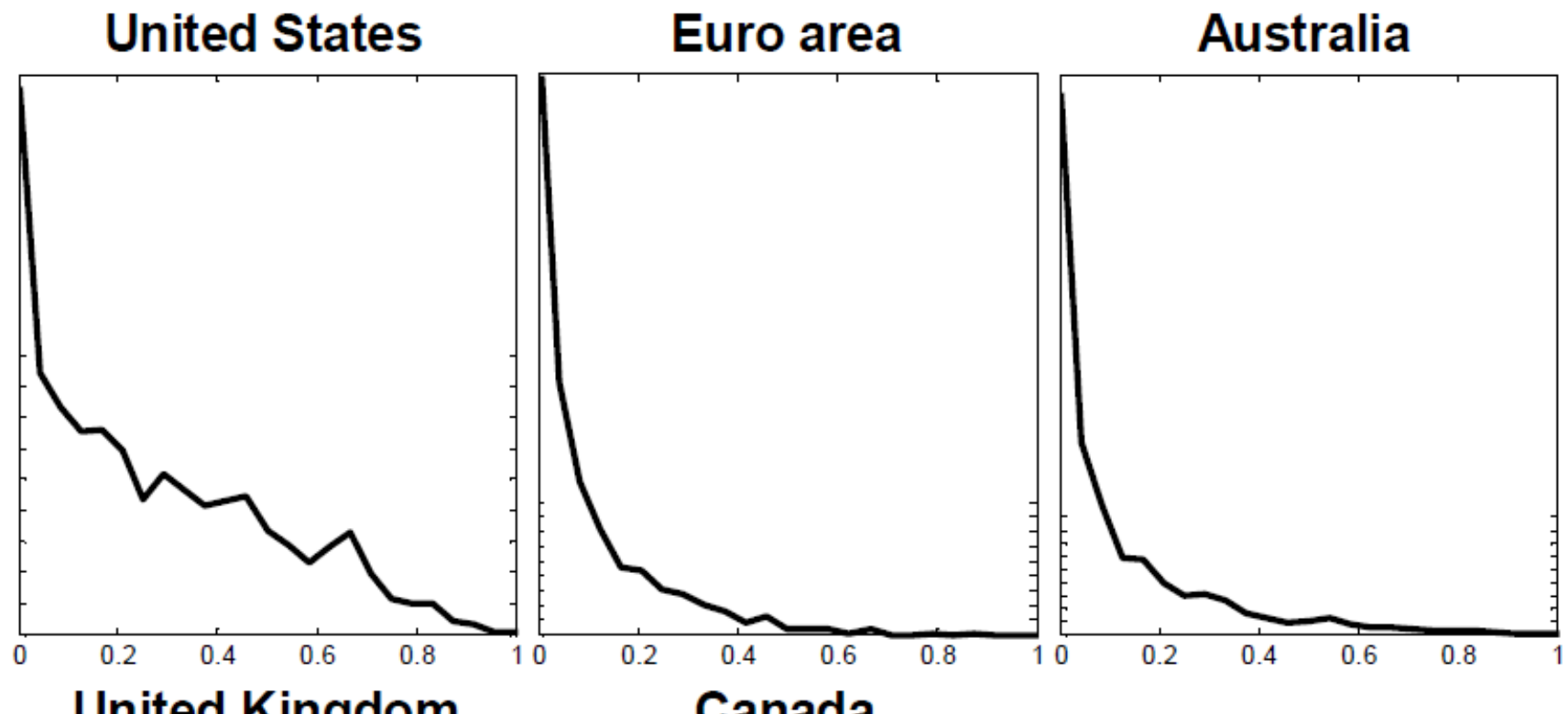

\section{United Kingdom}

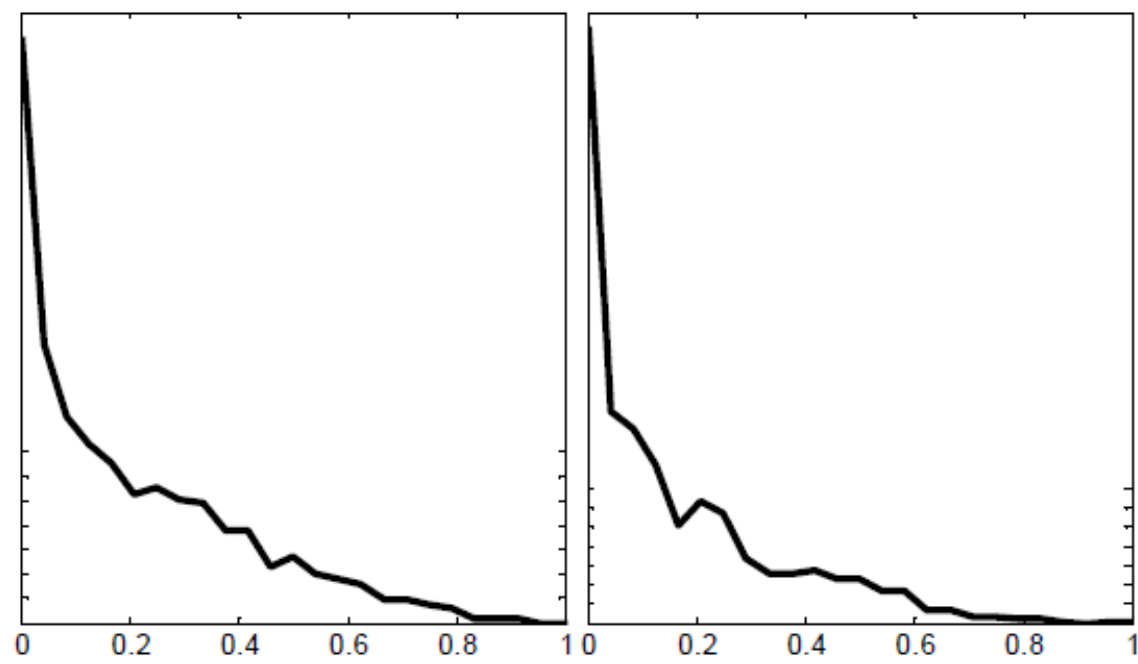

Figure 5 Results based on Bayesian VARs allowing for four permanent inflation shocks: posterior distribution of the fraction of the permanent component of the unemployment rate explained by monetary shocks 